\title{
A translational approach to dystroglycanopathies: a frequent type of muscular dystrophy
}

Sebahattin Cirak, Aff1 Aff2 Aff3

Corresponding Affiliation: Aff1

Haicui Wang,, Aff1 Aff2

Raul Heredia, $\stackrel{\text { Aff3 }}{ }$

Francesco Muntoni,, Aff4

Yetrib Hathout, $\frac{\text { Aff3 }}{}$

Peter Herkenrath,, Aff1

Jörg Dötsch, $\frac{\text { Aff1 }}{}$

Peter Nürnberg,

\begin{tabular}{|l|l|l|l||}
\hline \multicolumn{2}{|c|}{ ArticleInfo } \\
\hline \hline ArticleID & $:$ & 67 \\
\hline \hline ArticleDOI & $:$ & $10.1186 / 2194-7791-2-S 1-A 27$ \\
\hline \hline ArticleCitationID & $:$ & A27 \\
\hline \hline ArticleSequenceNumber & $:$ & 27 \\
\hline \hline ArticleCategory & $:$ & Meeting abstract \\
\hline \hline ArticleFirstPage & $:$ & 1 \\
\hline \hline ArticleLastPage & $:$ & 2 \\
\hline \hline ArticleHistory & $:$ & $\begin{array}{l}\text { RegistrationDate } \\
\text { OnlineDate }\end{array}$ \\
\hline \hline ArticleCopyright & & $\begin{array}{l}\text { Cirak et al.2015 } \\
\text { This article is published under license to BioMed Central } \\
\text { Ltd. This is an Open Access article distributed under the } \\
\text { terms of the Creative Commons Attribution License } \\
\text { (http://creativecommons.org/licenses/by/4.0), which permits }\end{array}$ \\
\hline $\begin{array}{l}\text { unrestricted use, distribution, and reproduction in any } \\
\text { medium, provided the original work is properly cited. }\end{array}$ \\
\hline
\end{tabular}

Aff1

Klinik und Poliklinik für Kinder- und Jugendmedizin, Universitätsklinikum Köln, Köln, Germany

Aff2

Institut für Humangenetik, Universitätsklinikum Köln, Köln, Germany

Aff3

Research Center for Genetic Medicine, Children's National Medical Center, Washington, DC, USA 
UCL Institute of Child Health, London, UK

Aff5

Universität Köln, Zentrum für Genomics, Köln, Germany

Abstracts of the 51st Workshop for Pediatric Research

51st Workshop for Pediatric Research

Göttingen, Germany

16-17 April 2015

This supplement has not been sponsored.

Meeting abstracts

\section{Meeting abstract}

The dystroglycanopathies (DGpathies) are a clinically and genetically diverse group of recessively inherited conditions ranging from the most severe Walker-Warburg syndrome (WWS), to mild forms of adult onset limb girdle muscular dystrophy (LGMD). The LGMD2I caused by the L276I mutation in fukutin-related protein $(F K R P)$ is common in the Caucasians population. Their hallmark is a reduction in the functional O-glycosylation of $\alpha$-dystroglycan. Unfortunately in about $50 \%$ of the patient's disease genes are unknown. Curative treatments are not available. To this end, we pursued a translational approach:

By whole exome sequencing, we have discovered 3 new genes (ISPD, B3GALNT2 and GMPPB). The biochemical function of isoprenoid synthase domain containing (ISPD) in mammals remain unknown. Remarkably, we identified a novel DGpathy phenotype harbouring mutations in ISPD characterized by LGMD, oculomotor apraxia, myopia and cerebellar hypoplasia.

To explore the possible effects of missense mutations, we have mapped them onto the homology model of human ISPD derived from the structure of a related bacterial protein (CDP-ME synthase; 1VPA). Of the four mutations identified in catalytic domain, two (A53TD and R126H) are predicted to significantly affect the catalytic activity of human ISPD whereas the mutations P149L and Y226C are likely to perturb the nearby secondary structure leading to destabilization of the mutant protein. We have expressed recombinant His-tagged wt and mut. ISPD protein in E.coli and purified Co-IMAC affinity chromatography. By the use of Thermofluor we could confirm the differences in the stability between wt and mut. ISPD proteins.

To enable clinical trials, we performed a pilot study for the discovery of serum biomarkers in LGMD2I and could identify various candidates which we grouped into a) myofibrillar proteins b) glycolytic enzymes, c) extracellular matrix and d) other muscle specific proteins. 